\title{
Employing Directed Internship and Apprenticeship for Fostering HPC Training and Education
}

\author{
Elizabeth Bautista \\ NERSC \\ Lawrence Berkeley National Laboratory \\ Berkeley, CA \\ ejbautista@lbl.gov
}

\author{
Nitin Sukhija \\ Department of Computer Science \\ Slippery Rock University of Pennsylvania \\ Slippery Rock, PA \\ nitin.sukhija@sru.edu
}

\begin{abstract}
Positions within High Performance Computing are difficult to fill, especially that of Site Reliability Engineer within an operational area. At the National Energy Research Scientific Computing Center (NERSC) at Lawrence Berkeley National Laboratory (LBNL), the Operations team manage the HPC computational facility with a complex cooling ecosystem and also serve as the wide area network operations center. Therefore, this position requires skill sets in four specific areas: system administration, storage administration, facility management, and wide area networking. These skills are not taught in their entirety in any educational program; therefore, a new graduate will require extensive training before they can become proficient in all areas. The proximity to Silicon Valley adds another challenge in finding qualified candidates. NERSC has implemented a new approach patterned after the apprenticeship program in the trades. This program requires an intern or apprentice to fulfill milestones during their internship or apprenticeship timeframe, with constant evaluation, feedback, mentorship, and hands-on work that allow candidates to demonstrate their growing skill that will eventually lead to winning a career position.
\end{abstract}

\section{KEYWORDS}

Site reliability engineer, HPC education, Training, Apprenticeship, Internship

\section{INTRODUCTION}

According to a 2008 analysis from the Public Policy Institute of California, it is projected that by 2025 , the number of college graduates will not meet the projected demand of the workforce [2] [1]. The analysis states that in recent decades the economic growth took place in a time-frame where there was significant growth in the number of workers with a college education. However, the analysis projects limitations due to a slower growth in the supply of college-educated workers in coming decades [3].

As part of succession planning, the National Energy Research Scientific Computing Center (NERSC) Operations team decided they needed to find a different way of recruiting talent and implemented a directed approach to both their internship and apprenticeship

Permission to make digital or hard copies of all or part of this work for personal or classroom use is granted without fee provided that copies are not made or distributed for profit or commercial advantage and that copies bear this notice and the full citation on the first page. To copy otherwise, or republish, to post on servers or to redistribute to lists, requires prior specific permission and/or a fee. Copyright $\odot$ JOCSE a supported publication of the Shodor Education Foundation Inc.

(c) 2021 Journal of Computational Science Education https://doi.org/10.22369/issn.2153-4136/12/2/8 programs [8]. Not only do these programs allow them to identify and recruit more qualified and committed candidates, but they also help in retaining them for a career position.

This paper documents the process of the directed internship and apprenticeship programs in this format. Section 2 provides the background of how unsuccessful recruiting and retention processes lead to this decision. Section 3 explains the difference between the internship and apprenticeship programs. Section 4 explains the logistics such as how the program works, what are the essential parts, and what makes it work. Section 5 provides positive outcomes, and Section 6 provides final thoughts.

\section{BACKGROUND}

When NERSC moved from Livermore to Berkeley in 1995, the 24x7 Operations Team was a group of 9 technicians who used written manuals from the systems and storage groups. They followed a specific set of directions then engaged the person on call, who would eventually solve the problem. Because these positions had a standard operations procedure (SOP), it was not difficult to recruit for talent, as long as they can follow directions. The team were onsite $24 \times 7$ across three eight-hour shifts. As technicians, they were eligible for overtime. This was not a deterrent for recruiting and retaining talent.

With an incoming new manager in 2011, the team decided they wanted to grow professionally in order to have more control over their area. Through professional development, the team's classification was changed to Site Reliability Engineer, and they became salaried staff, much higher in range than the previous technician classification. The team had upgraded their daily work such that they were now managing systems, storage environments and the wide area network.

With the impending move to a new and state-of-the-art building in 2015, they were poised to manage not only a more sophisticated water cooled system but also a building ecosystem that could support their path to exascale. Managing operations in this type of environment requires staff who must, in addition to system administration, understand power, infrastructure and cooling requirements demanded by the ecosystem. Such complexity and scale provide unique challenges, including usage fluctuations and providing high availability and high utilization for users who need to have their jobs run in spite of failures or cooling requirements involving both air and water. The additional skill set now also required knowledge of mechanical and electrical engineering. Because of the new classifications, the prior pipeline stopped providing qualified candidates. Rather, candidates who applied to the position would be knowledgeable in one or two areas, and the team would need to 
train for the additional two areas. The current position now directly competes with highly sought-after skillsets in Silicon Valley, which makes it much more challenging to retain candidates. Within a year or two, the new hire would eventually leave, noting that they were unhappy with the off-shift and had found a position elsewhere working a standard 9-5, Monday through Friday. Retention became especially challenging during the holidays, where the staff continued to be onsite while all others have the paid time off. This short retention required the team to constantly have to restart training a new person, if they can recruit an adequate candidate.

According to the 2010's high-tech employment report by the Public Policy Institute of California, $12.6 \%$ of all employments in the computer industry are with Silicon Valley companies, which accounts for fifteen times the national average. Moreover, other cities only employ $3 \%$ or less in the computer industry [5] [4] [6].

Realizing that the higher classification meant they were competing much more with Silicon Valley companies who tend to recruit them out of NERSC, even if their training is not complete, the team decided on a new approach; they would grow their workforce. In this way, they could also determine the commitment of the individual as they were learning the skill [11].

\section{DEFINITIONS}

\subsection{Directed Internship}

An internship is the position of a student or trainee who works in an organization, sometimes without pay, in order to gain work experience or satisfy requirements for a qualification or to earn credits.

In this case, interns are still in school and usually worked twenty hours during the school term and full-time when they are out of school, such as in between term breaks or the summer. They can either be directly hired and paid, or if they are earning credits for the internship, this is arranged through their school and NERSC's affiliate program.

Upon discussion with the intern, they are provided with a specific project to work on that allows them hands-on practice of a skill that they already studied in school. The directed internship provides them the opportunity to work on a real-world project that is implemented at the workplace.

Interns can work for additional school terms and in the summer to learn additional skills until, if they choose, they graduate. At this point, they can be prepared to compete for a career position or choose to enter the apprenticeship program [9] to finetune their skill.

\subsection{Directed Apprenticeship}

An apprenticeship is an effective work-based learning strategy that creates pathways to career advancement and higher wages through hands-on experience. The program can provide access to successful career on-ramps for targeted worker populations, such as disadvantaged youth, veterans, and women in non-traditional fields.

Apprentices are usually close to or at the end of their educational program and are ready to commit to a full-time training program. They are hired for a one-year paid term with the understanding that they have milestones to fulfill. Successful completion of these milestones gives them a very high degree of leverage in competing for a career position in twelve months [7].

\section{LOGISTICS}

\subsection{Assumptions of the Program Participants}

The expectation of the intern or apprentice is that they are working in a realm of adult education and preparation. They should be capable adults who have the ability to express their needs, their problems, and their interests, and they should be able to make the type of decisions that adults normally make. They should have the ability to choose, when appropriately informed, the situation or environment for experiential learning. For example, an apprentice is given a task to complete within a timeframe. After two weeks and much research, they find that they need a book. They should be able to make the decision to either purchase the book and ask if there is a reimbursement process or ask their supervisor to purchase the book for them. Further, if there is a class they need to take that is a one-week seminar, they should also be able to ask this of their supervisor.

Since we are in the business of educating adults, this includes assumptions and attitude of trust. Interns and apprentices are capable of discerning effective and/or appropriate behavior in others, especially when given the encouragement to reflect upon their observations. For example, an intern should be able to tell their supervisor that the person assigned to work with them on their technical project does not explain things in a way they can understand. They also need to trust the supervisor that they can come to a mutually beneficial agreement or solution.

It has been our experience that participants who are more successful in the program are those who are mature, sometimes secondcareer individuals with more work experience, even if it is not in the computer science field. They are more thoughtful, are serious about their education and training, and have an idea of their career path. The advantage of this program is that they are constantly being mentored and managed to work with actual staff who perform the job for which they will eventually compete, most of the time, in a one-on-one approach.

\subsection{The Directed Approach}

The goal of the program is to successfully train and expose participants daily to the job toward which they will eventually compete. As such, training is hands-on based on what they learned in school. For example, if they took a class in Python, they will be assigned to write a Python program. If they took a class in system administration, they will assist in managing the HPC systems. They work side-by-side with the individual, and this provides daily insight into their working environment. After some training, the participant will eventually, under direct supervision, perform the role to diagnose and triage problems. Then they are debriefed on their performance and provided feedback on constant improvement.

This type of learning promotes the participant's sense of responsibility and ownership toward the experience. As they strengthen their skill, they continue to perform with less supervision on one skill as they practice a new skill until they complete a milestone. They continue to complete milestones until they are ready to compete for a career position. 
During this time, they perform the daily operational tasks to manage a data center, they are given one to two projects that they complete, and they are given a larger project that they must present to the management before implementation. Each skill is tightly practiced and developed, even the public speaking and presentation techniques.

\subsection{What Makes It Work?}

Certain processes need to occur in order to make this program work.

\subsubsection{Administrative}

Work with Human Resources to create a position description for both the apprentice and intern. The intern position should highlight that the participant will learn a skill through working on and completing the project.

The apprentice position should list required skills that will allow the participant to practice what they learned in school. Further, the position description should be the entry-level position for the career they will compete for at the end of the program.

It should be the goal of the organization to minimize the idea that apprentices and interns are free help, i.e. irrelevant. Do not provide work that is easy with little training or supervision, repetitive work, or work that the participant already knows how to perform. The help they provide should be almost at the level of your current staff.

\subsubsection{Mentors, Trainers and Attitudes}

It is essential to identify staff who like to train and work with a person one-on-one as part of their day. They should consistently have a positive attitude toward the participants and their job.

The mentor or trainer should understand that participants will solve problems any way they can, so encourage them to use their strongest skills. Treat them like they are fresh eyes, and allow them to provide you feedback of how to make a process more efficient.

"Everyone learns how to survive with minimal training, unless a teacher, "systems manager" can design a strategy for ensuring that staff cope with their deficiencies as well as utilize their strengths."[10].

It is also important to identify a supervisor who can technically evaluate progress and set milestones, and they need to work closely with the mentor or trainer. This person needs to have a clear understanding of the role of the trainer and the role of the participant. They monitor progress and, if needed, troubleshoot an interaction or a teaching issue and implement corrective actions. For example, provide more challenging training if the participant seems to learn quicker than usual. They need to be highly accessible to both parties to be a soundboard, role play, provide advice on paths or solutions, or even to assist in navigating a course of action. Finally, this person can serve as a model for the aspiring professional.

Lastly, there needs to be an individual that understands the hiring process of the organization. They can help the manager navigate the hiring process, help evaluate readiness from a "paper" standpoint. For example, they can assist in evaluating the participant's resume and determine if the candidate is ready, at least on paper.
4.3.3 Why does it work?

The participant gains a variety of experiences and sees what is being done in the job they want to acquire.

Having different roles separated provides a higher quality of supervision and exposes the participant to many more staff in the organization.

The psychological benefits are numerous, including the following:

- The idea that it is a workplace, not campus, and provides a "real world" feel.

- Exposure to different roles, providing a feeling that they can find a niche in the organization.

- Many more networking opportunities and role models.

- Coming from a school environment, it provides a clean slate, especially for a second-career individual.

- They develop self-confidence and an improved self-image. (You have no idea how many of my apprentices call themselves Site Reliability Engineers).

- They perform operational work that needs time management and work management, and they find their place in the overall workplace.

As part of recruitment, we need to explain an apprenticeship or even a directed internship; therefore, we engage more with the community and community schools. A participant who comes from a particular community feels like they represent the community and will continue the engagement when they are hired.

As an economic benefit to the organization, apprenticeships are less expensive than directly hiring and not retaining, and because we are engaging the community, there is potential for developing a workforce pipeline.

\section{POSITIVE OUTCOMES}

Below are statistics of the directed apprenticeship program from January 2015 through December 2019.

- NERSC Operations has had 25 apprentices.

- Of these, SIX have been fully retained in a career position.

- THREE have completed the program and accepted a position elsewhere. This is considered a win.

- FOUR opted to continue toward a higher education, which we also consider a win.

- THREE are currently in the program. (As of January 2021, 1 was hired, 2 went on to a graduate program.)

- NINE did not complete the program.

\section{CONCLUSION AND FURTHER WORK}

The positive outcomes of the program show that NERSC Operations is able to recruit quality talent, retain more individuals, or encourage individuals to further their education. Even those who decided to find a position elsewhere were able to find a job at a higher pay level than they would have without the apprenticeship. Overall, it has had a positive impact, not only for NERSC Operations, but also for the individuals themselves.

In terms of fostering HPC education and training, the program itself exposes participants to a subject rarely taught in school. The more they work in this niche, the more they become familiar with the "topics" they need to learn, practice, and eventually grow into. 
Participants take this knowledge and apply it once they become career individuals and seek out education and training opportunities toward their professional development accordingly. The program works due to the constant evaluation to meet milestones.

Our assessment of success is determined by the retention of the apprentice as a hired individual. Because of this program, NERSC Operations is now fully staffed.

This program is generic enough that it can be used in any situation: for example, to diversify your workforce. The pandemic that started in 2019 has provided us the challenge of staff not being able to work side-by-side with their mentors. However, we leveraged technology to be able to continue the program.

\section{ACKNOWLEDGMENTS}

This research used resources of the National Energy Research Scientific Computing Center (NERSC), a U.S. Department of Energy Office of Science User Facility operated under Contract No. DEAC02$05 \mathrm{CH} 11231$.

\section{REFERENCES}

[1] [n. d.]. California 2025: Taking on the Future. https://www.ppic.org/content/ pubs/report/R_605MB2R.pdf. Accessed: 2021-01-14.

[2] [n. d.]. California's Need for Skilled Workers. https://www.ppic.org/publication/ californias-need-for-skilled-workers/. Accessed: 2021-01-14.

[3] [n. d.] Can Apprenticeships Train the Workforce of the Future? States Hope So. https://www.governing.com/topics/mgmt/ gov-work-study-student-debt-apprenticeships.html. Accessed: 2021-0114.

[4] [n. d.]. Can California Import Enough College Graduates to Meet Workforce Needs? https://www.ppic.org/content/pubs/cacounts/CC_507HJCC.pdf. Accessed: 2021-01-14.

[5] [n. d.]. High-Tech Employment In California. https://www.ppic.org/content/ pubs/jtf/JTF_HighTechEmpJTF.pdf. Accessed: 2021-01-14.

[6] [n. d.]. High-Tech Employment in California. https://www.ppic.org/content/ pubs/jtf/JTF_HighTechEmpJTF.pdf. Accessed: 2021-01-14.

[7] [n. d.]. Why Apprenticeship Works. https://www.ajactraining.org/ why-apprenticeship-works/. Accessed: 2021-01-14.

[8] Liliane Bonnal, Sylvie Mendes, and Catherine Sofer. 2002. School-to-work transition: apprenticeship versus vocational school in France. International fournal of Manpower (2002)

[9] Barbara LeGrand Brandt, James A Farmer Jr, and Annette Buckmaster. 1993. Cognitive apprenticeship approach to helping adults learn. New directions for adult and continuing education 1993, 59 (1993), 69-78.

[10] Edgar S Cahn. 1980. Clinical Legal Education from a Systems Perspective. Clev. St. L. Rev. 29 (1980), 451

[11] Lisa M Lynch. 2007. Training and the private sector: international comparisons. University of Chicago Press. 